\title{
Current Issues Involving the Treatment of Small Rectal Carcinoid Tumors
}

\author{
Dae Kyung Sohn \\ Center for Colorectal Cancer, National Cancer Center, Goyang, Korea
}

\section{See Article on Page 201-204}

Recently, the number of cases of neuroendocrine tumors, mainly small rectal carcinoid tumors detected during colonoscopy screening, has increased rapidly $[1,2]$. However, a standardized management for small rectal carcinoid tumors still remains to be established. Thus, several issues remain to be addressed.

First, which tumors have high risk for lymph-node metastasis? Small rectal carcinoid tumors without metastasis can be treated by using local excision methods, including endoscopic resection or local surgical excision. Tumor size, the depth of invasion, the presence of angiolymphatic invasion, and the mitotic rate have been shown to be risk factors for lymph-node metastasis [3-5]. However, identifying the high-risk group preoperatively is difficult. Preoperative endoscopic ultrasonography or computed tomography (CT) may be helpful, but the clinical role of those modalities is limited. In fact, Kim et al. [6] reported that fewer than half of the 38 patients enrolled in the study had received preoperative radiologic evaluations.

Second, which is the best method to use for the local resection of tumors? The tumors are usually located in the submucosal layer; thus, achieving a tumor-free margin by using a conventional endoscopic resection, such as a snare polypectomy or a strip biopsy, is difficult. Recently, Son et al. [7] reported pathologically-determined complete-resection (P-CR) rates for small rectal carcinoid tumors excised by using several methods. The P-CR rates were $30.9 \%, 72.0 \%$, and $81.8 \%$ for a conventional endoscopic polypectomy, an advanced endoscopic technique, including endoscopic mucosal resection with cap or endoscopic

Correspondence to: Dae Kyung Sohn, M.D.

Center for Colorectal Cancer, National Cancer Center, 323 Ilsan-ro,

Ilsandong-gu, Goyang 410-769, Korea

Tel: +82-31-920-1636, Fax: +82-31-920-1289

E-mail: gsgsbal@ncc.re.kr

(C) 2012 The Korean Society of Coloproctology

This is an open-access article distributed under the terms of the Creative Commons Attribution NonCommercial License (http://creativecommons.org/licenses/by-nc/3.0) which permits unrestricted noncommercial use, distribution, and reproduction in any medium, provided the original work is properly cited. submucosal dissection, and local surgical excision, including transanal excision and transanal endoscopic microsurgery (TEM). In a study by Kim et al. [6], the complete resection rate for TEM was over $97 \%$. Although TEM is superior to other endoscopic procedures, TEM must be considered to be more invasive because of the risk associated with the use of anesthesia.

Third, guidelines for follow-up examination after initial treatment for a small rectal carcinoid tumor have not yet been established. Some authors recommend annual follow-up examination including a CT scan while others suggest that follow-up is not necessary [8-11]. Actually, Kim et al. [6] reported that only 38 patients of 109 patients with a rectal carcinoid tumor who had undergone TEM had more than three years of follow-up.

Regretfully, the study of Kim et al. [6] is one of small case series on the treatment of rectal carcinoid tumors. Hopefully, largescale multicenter studies on the management of rectal carcinoid tumors will be reported sooner or later.

\section{REFERENCES}

1. Yao JC, Hassan M, Phan A, Dagohoy C, Leary C, Mares JE, et al. One hundred years after "carcinoid": epidemiology of and prognostic factors for neuroendocrine tumors in 35,825 cases in the United States. J Clin Oncol 2008;26:3063-72.

2. Scherubl H. Rectal carcinoids are on the rise: early detection by screening endoscopy. Endoscopy 2009;41:162-5.

3. Soga J. Early-stage carcinoids of the gastrointestinal tract: an analysis of 1914 reported cases. Cancer 2005;103:1587-95.

4. Modlin IM, Kidd M, Latich I, Zikusoka MN, Shapiro MD. Current status of gastrointestinal carcinoids. Gastroenterology 2005; 128:1717-51.

5. Fahy BN, Tang LH, Klimstra D, Wong WD, Guillem JG, Paty PB, et al. Carcinoid of the rectum risk stratification (CaRRs): a strategy for preoperative outcome assessment. Ann Surg Oncol 2007; 14:1735-43.

6. Kim HR, Lee WY, Jung KU, Chung HJ, Kim CJ, Yun HR, et al. Transanal endoscopic microsurgery for the treatment of well-differentiated rectal neuroendocrine tumors. J Korean Soc Coloproctol 2012;28:201-4. 
7. Son HJ, Sohn DK, Hong CW, Han KS, Kim BC, Park JW, et al. Factors associated with complete local excision of small rectal carcinoid tumor. Int J Colorectal Dis 2012 Jul 22 [Epub]. http:// dx.doi.org/10.1007/s00384-012-1538-z.

8. Holinga J, Khalid A, Fasanella K, Sanders M, Davison J, McGrath K. Metastatic risk of diminutive rectal carcinoid tumors: a need for surveillance rectal ultrasound? Gastrointest Endosc 2012;75: 913-6.

9. Murray SE, Sippel RS, Lloyd R, Chen H. Surveillance of small rectal carcinoid tumors in the absence of metastatic disease. Ann Surg Oncol 2012 Jun 16 [Epub]. http://dx.doi.org/10.1245/s10434- 012-2442-z.

10. Ramage JK, Ahmed A, Ardill J, Bax N, Breen DJ, Caplin ME, et al. Guidelines for the management of gastroenteropancreatic neuroendocrine (including carcinoid) tumours (NETs). Gut 2012;61: 6-32.

11. National Comprehensive Cancer Network [Internet]. Fort Wathington: National Comprehensive Cancer Network; c2012 [cited 2012 Jun 30]. NCCN clinical practice guidelines in oncology (NCCN Guidelines): neuroendocrine tumors. ver. 1.2012. Available from: http://www.nccn.org/professionals/physician_gls/f_ guidelines.asp. 